\title{
The immobilisation of heavy metals from sewage sludge ash in geopolymer mortars
}

\author{
Mateusz Sitarz ${ }^{1, *}$, Tomasz Zdeb ${ }^{1}$, João Castro Gomes ${ }^{2}$, Erick Grünhäuser Soares ${ }^{2}$, \\ and Izabela Hager $^{1}$ \\ ${ }^{1}$ Cracow University of Technology, Faculty of Civil Engineering, Chair of Building Materials, \\ Warszawska 24, 31-155 Cracow, Poland \\ ${ }^{2}$ University Beira Interior, Department of Civil Engineering and Architecture, Convento de Sto. \\ António. 6201-001 Covilhã, Portugal
}

\begin{abstract}
Sewage sludge is a semi-solid waste material created as a result of the sewage treatment of industrial or municipal wastewater. Because the laws and regulations of the European Union require not only a reduction in waste generation but also the preparation of waste for reuse and disposal, it is necessary to look for new methods of the application of sewage sludge as part of sustainable waste management. In this study, ash formed as a result of the combustion of sewage sludge from the sewage treatment plant in Płaszów, Krakow in a fluidised bed furnace at a temperature of around $800^{\circ} \mathrm{C}$ was used. Sewage sludge ash (SSA) contains over $30 \% \mathrm{SiO}_{2}$ and approx. $10 \% \mathrm{Al}_{2} \mathrm{O}_{3}$, which indicates potential applications in geopolymer materials. In this study, samples of geopolymer mortars with a binder containing sewage sludge ash as well as fly ash (FA) and ground granulated blast furnace slag (GGBFS) were prepared. The mechanical parameters were determined after 2, 7, 14, and 28 days. The results show that the sewage sludge ash-based geopolymer shows binding properties at ambient temperature and, depending on the presence of FA and/or GGBFS, the compressive strength varies from 5 to $45 \mathrm{MPa}$ after 28 days. The aim of the research was also to determine the total content of heavy metals ( $\mathrm{Sb}$, $\mathrm{As}, \mathrm{Cr}, \mathrm{Cd}, \mathrm{Cu}, \mathrm{Ni}, \mathrm{Pb}, \mathrm{Hg}, \mathrm{Zn}$ ) in the raw materials used and their leachability from the structure of the hardened materials. Immobilisation of heavy metals is very promising. Based on the results of tests, it seems possible to use SSA in geopolymer materials, but not as the main component of the binder.
\end{abstract}

\section{Introduction}

Geopolymers are one of the most intensively developed groups of alternative inorganic binders. Due to their mechanical properties and durability in various environments, particularly in high temperature conditions, the possibility for the immobilisation of heavy metals and their reduced environmental impact has become a frequent subject of research in the context of the production of sustainable building materials [1, 2, 3, 4]. Geopolymers

\footnotetext{
*Corresponding author: mateusz.sitarz@pk.edu.pl
} 
belong to the group of aluminosilicate materials synthesized in an alkaline environment. In Poland, the first research works on these binders were carried out by professor $\mathrm{J}$. Małolepszy [5]. Geopolymers have a three-dimensional structure and are formed as a result of the polycondensation reaction of an aluminosilicate precursor in an alkaline environment [6]. Among the raw materials used as a precursor, we can distinguish natural (volcanic ashes, diatomaceous earth), synthetic (metakaolin) and waste materials (fly ash, blast furnace slag, ceramics, mining wastes, glass, sludge ash) [7,8].

Among the waste materials is sewage sludge ash (SSA) which is produced by the combustion of sewage sludge from treatment plants [9]. According to European Union data [10], SSA production in Europe is estimated at a level of from $0.1 \mathrm{~kg}$ up to $30.8 \mathrm{~kg}$ per population equivalent per year (kg/p.e/year). In terms of composition, SSA mainly contains $\mathrm{SiO}_{2}, \mathrm{Al}_{2} \mathrm{O}_{3}, \mathrm{Fe}_{2} \mathrm{O}_{3}, \mathrm{CaO}, \mathrm{MgO}$ and $\mathrm{P}_{2} \mathrm{O}_{5}$. Current research shows various potential opportunities for SSA utilisation, including the use of clay and SSA for the production of bricks [11], tiles [12] and lightweight aggregates [13]. Furthermore, attempts are being made to use SSA as an additive to partially replace cement in the production of mortars and concretes [14].

The main factor determining the attempts of SSA application in mineral binders is the content of amorphous $\mathrm{SiO}_{2}$ and $\mathrm{Al}_{2} \mathrm{O}_{3}$ in its composition and the possible pozzolanic properties of the material resulting from this [15].

The chemical composition also indicates the potential possibility of using SSA as a precursor in geopolymer binder technology. Apart from alkaline metal cations, $\mathrm{SiO}_{2}, \mathrm{Al}_{2} \mathrm{O}_{3}$ and $\mathrm{CaO}$ oxides are considered to be the basic compounds building the geopolymer structure [16]. Currently, knowledge regarding the utilisation of SSA in geopolymer materials is limited in the literature.

Tashima et al. [17] analysed the mechanical properties of a geopolymer with a mixed precursor consisting of GGBFS (80wt.\%) and SSA (20wt.\%). After 90 days, the compressive strength of the composite was $31 \mathrm{MPa}$. The studies carried out by Chakraborty et al. [18] concerned a geopolymer containing $20 \mathrm{wt} . \%$ of quicklime, $10 \mathrm{wt} . \%$ of blast furnace slag and $70 \mathrm{wt} . \%$ of SSA produced with a sodium hydroxide solution. After 28 days, the material achieved a compressive strength of $31.3 \mathrm{MPa}$

Yamaguchi and Ikeda [19] noted the slow time of the bonding of the geopolymer with SSA at room temperature. The results of the conducted observations concern both systems containing only SSA and solutions using mixes of SSA and FA. Conclusions from the research conducted by Paulnath et al. [20] show a decrease in the strength of geopolymer concrete with increases in the share of SSA and simultaneous reductions of the FA content in the mixture. The results of studies carried out by Yamaguchi [19] show that the addition of SSA may improve the strength of the FA-based geopolymers but only in the case of additional heat being applied during bonding.. The data available in the literature indicate that the most efficient use of SSA in geopolymer technology is possible with mixed systems containing GGBFS.

Aside from the mechanical and durability characteristics, an important aspect of the development of modern building materials is the widely addressed environmental context. Municipal waste is a source of environmental pollutants, including heavy metals [21, 22]. Progressive urbanisation and industrial development generate serious environmental problems and the need to search for solutions that enable the management of waste while neutralising environmentally hazardous chemicals.

Heavy metal immobilisation is the process of mixing waste containing heavy metals with a binder (e.g. cement or geopolymer) to immobilise and reduce the bioavailability of the heavy metals [23, 24, 25]. Mechanisms of heavy metals immobilization in mineral binders were the subject of research, among others, by W. Nocuń-Wczelik [26] and J. Deja [27]. 
Geopolymer binders show very good possibilities for heavy metal immobilisation and, at the same time, high durability of the material $[28,29]$. The effect of the immobilisation of heavy metals in the geopolymer structure is related to the nature of the chemical bonds formed in the material.

The aim of the study was to analyse the possibility of using SSA to produce a geopolymer binder cured at ambient temperature together with the assessment of the level of immobilisation of the heavy metals contained in SSA in the geopolymer matrix.

\section{Materials and experimental procedures}

Three different base materials were used to prepare the geopolymer mortars. Sewage sludge ash (SSA) was obtained from the sewage treatment plant in Płaszów in Krakow; this was formed as a result of the combustion of sewage sludge in a fluidised bed furnace at a temperature of around $800^{\circ} \mathrm{C}$. SSA contains over $30 \mathrm{wt} . \% \mathrm{SiO}_{2}$ and approx. $10 \mathrm{wt} . \% \mathrm{Al}_{2} \mathrm{O}_{3}$. Fly ash (FA) had $\mathrm{SiO}_{2}(52 \mathrm{wt} . \%)$ and $\mathrm{Al}_{2} \mathrm{O}_{3}(28 \mathrm{wt} . \%)$ as the main components. According to ASTM C618, this type of ash is categorised as Class F, which is from the group of low $\mathrm{CaO}$ fly ashes. The ash used also meets the requirements of EN 450-1: 2012 and can be used as an additive in cement concrete. Ground granulated blast furnace slag (GGBFS) had calcium oxide (44wt.\%) and silicon oxide (39wt.\%) as the main chemical components. The oxide compositions of all the precursors used are presented in Table 1.

Table 1. The oxide composition of the precursors.

\begin{tabular}{|l|c|c|c|c|c|c|c|c|c|c|}
\hline $\begin{array}{c}\text { Element } \\
\text { \%wt. }\end{array}$ & $\mathbf{S i O}_{2}$ & $\mathrm{Al}_{2} \mathrm{O}_{3}$ & $\mathbf{C a O}$ & $\mathrm{Fe}_{2} \mathrm{O}_{3}$ & $\mathbf{M g O}$ & $\mathbf{N a}_{2} \mathrm{O}_{\mathbf{e}}$ & $\mathbf{K}_{2} \mathbf{O}$ & $\mathbf{S O}_{3}$ & $\mathbf{P}_{2} \mathrm{O}_{5}$ & $\mathbf{T i O}_{2}$ \\
\hline SSA & 31.41 & 10.20 & 14.22 & 21.02 & 1.70 & 1.23 & - & 2.11 & 18.01 & - \\
\hline FA & 52.30 & 28.05 & 3.05 & 6.32 & 1.71 & 0.76 & 2,51 & 0.28 & 0.69 & 1.35 \\
\hline GGBFS & 39.31 & 7.61 & 43.90 & 1.49 & 4.15 & 0.70 & 0.36 & 0.51 & - & - \\
\hline
\end{tabular}

An alkaline solution was used in the synthesis of the geopolymer binder, which was prepared with Geosil® 34417 sodium silicate solution with additional water. The prepared alkaline solution was characterised by a molar ratio of silica to sodium oxide in the solution of $\mathrm{MR}=1.7$ and contained the total amount of water introduced into the mortar. In order to ensure the appropriate workability of mortars with different precursors, the consistency of the mixtures was adjusted by the amount of alkaline solution introduced.

Table 2. Properties of the sodium silicate solution.

\begin{tabular}{|l|c|c|}
\hline \multicolumn{1}{|c|}{ Characteristic } & Sodium silicate solution & Unit \\
\hline $\mathrm{Na}_{2} \mathrm{O}$ content & 12.6 & wt.\% \\
\hline $\mathrm{SiO}_{2}$ content & 20.8 & wt. $\%$ \\
\hline water content & 66.6 & wt. $\%$ \\
\hline density & 1.42 & $\mathrm{~g} / \mathrm{cm}^{3}$ \\
\hline molar ratio $\left(\mathrm{MR}=\mathrm{mol} \mathrm{SiO}_{2} / \mathrm{molNa}_{2} \mathrm{O}\right)$ & 1.70 & - \\
\hline
\end{tabular}

The process of mortar preparation was carried out in stages and it was an experimental research. In the first stage, the geopolymer paste was prepared. The alkaline solution was added to the mineral precursor and the consistency of the mixture was observed during mixing. Depending on the degree of workability of the binder, further portions of the alkaline solution were added. After obtaining a suitable consistency, standard sand was introduced into the binder. Mixtures containing SSA were characterised by their significantly less liquid consistency compared to the FA-based mixtures with the same amount of alkaline solution. Four different types of mortars differing in their precursor type 
and alkaline solution content were prepared. Samples of 40x40x160 mm were prepared for testing the mechanical properties. Samples were hardened and cured at an ambient temperature $\left(\mathrm{T}=18 \pm 2^{\circ} \mathrm{C}, \mathrm{RH}=75 \%\right)$, no additional heating was used. All samples except the $100 \%$ FA mortar were removed from the moulds after two days. Due to the low degree of material bonding, the mortar containing only FA as a precursor was removed from the moulds after 7 days. Samples for determining the leachability of the heavy metals were prepared after 28 days of curing. The tests were carried out according to PN EN 12457. The mortars were crushed, ground and screened by fraction sizes $4 / 10 \mathrm{~mm}$. Then, $100 \mathrm{~g}$ of the sample was put in $1 \mathrm{dm}^{3}$ of water. All samples for all types of tests were protected with foil until the time of testing in order to limit the exchange of moisture with the environment. Table 3 below shows the compositions of mixtures per $1 \mathrm{~m}^{3}$ of mortar.

Table 3. Geopolymer mortars compositions for $1 \mathrm{~m}^{3}$ of mortar.

\begin{tabular}{|l|c|c|c|c|c|}
\hline \multicolumn{1}{|c|}{ Components } & 100\%FA & $\mathbf{1 0 0 \% S S A}$ & $\begin{array}{c}\text { 100\%GGBF } \\
\text { S }\end{array}$ & $\begin{array}{c}\text { 50\%FA+ } \\
\mathbf{5 0 \% S S A}\end{array}$ & $\begin{array}{c}\text { 50\%SSA+ } \\
\mathbf{5 0 \%} \\
\text { GGBFS }\end{array}$ \\
\cline { 2 - 6 } & $\left(\mathrm{kg} / \mathrm{m}^{3}\right)$ & $\left(\mathrm{kg} / \mathrm{m}^{3}\right)$ & $\left(\mathrm{kg} / \mathrm{m}^{3}\right)$ & $\left(\mathrm{kg} / \mathrm{m}^{3}\right)$ & $\left(\mathrm{kg} / \mathrm{m}^{3}\right)$ \\
\hline $\begin{array}{l}\text { Alkaline solution }(\mathrm{Na} \text {-Sil+extra } \\
\text { water) }\end{array}$ & 330.9 & 618.5 & 366.3 & 513.8 & 486.5 \\
\hline SSA $\left(2.9 \mathrm{~g} / \mathrm{cm}^{3}\right)$ & - & 618.5 & - & 326.3 & 360.4 \\
\hline FA $\left(2.1 \mathrm{~g} / \mathrm{cm}^{3}\right)$ & 735.3 & - & - & 326.3 & \\
\hline GGBFS $\left(2.9 \mathrm{~g} / \mathrm{cm}^{3}\right)$ & - & - & 813.9 & - & 360.4 \\
\hline Sand 0/2 mm $\left(2.65 \mathrm{~g} / \mathrm{cm}^{3}\right)$ & 1103.0 & 927.7 & 1220.9 & 978.8 & 1081.1 \\
\hline Mortar parameters & 1.5 & 1.5 & 1.5 & 1.5 & 1.5 \\
\hline sand to binder weight ratio & 0.45 & 1.0 & 0.45 & 0.78 & 0.67 \\
\hline $\begin{array}{l}\text { alkaline solution to binder } \\
\text { (FA+GGBFS+SSA) weight ratio }\end{array}$ & 0.30 & 0.65 & 0.30 & 0.52 & 0.45 \\
\hline $\begin{array}{l}\text { water to binder } \\
\text { (FA+GGBFS+SSA) weight ratio }\end{array}$ & \multicolumn{5}{|l}{} \\
\hline
\end{tabular}

\section{Results and discussion}

The results of the mixture consistency measurement are presented in Table 4 . In the case of blended precursors, a similar consistency was achieved. The degree of liquidity of the mortar with a precursor of just SSA and GGBFS was higher.

Table 4. Consistency of mortar according to PN-EN 1015-3 (average value after 15 strokes).

\begin{tabular}{|c|c|c|c|c|c|}
\hline \multirow{2}{*}{ Mortar } & $100 \%$ FA & $100 \%$ SSA & 100\%GGBFS & $\begin{array}{c}\text { 50\%FA+ } \\
\text { 50\%SSA }\end{array}$ & $\begin{array}{c}\text { 50\%SSA+ } \\
\text { 50\%GGBFS }\end{array}$ \\
\cline { 2 - 6 } & {$[\mathrm{cm}]$} & {$[\mathrm{cm}]$} & {$[\mathrm{cm}]$} & {$[\mathrm{cm}]$} & {$[\mathrm{cm}]$} \\
\hline Flow & 11 & 18 & 19 & 14 & 13 \\
\hline
\end{tabular}

Figure 1 shows the changes of bulk density depending on the composition of the mortar. The differences between the individual materials are mainly due to the different mineral densities and the different amounts of alkaline solution used. Small changes in density over time can be of chemical origin and be related to the progressing material bonding reaction. 


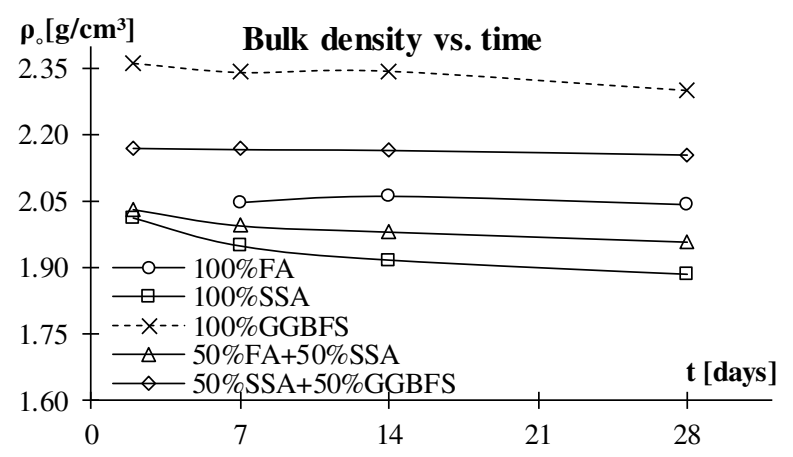

Fig. 1. Bulk density of the geopolymer mortar specimens.

The bending and compressive strength test methodology corresponded to the procedures set out for cement mortars (according to PN-EN 196-1). The results of the strength tests show a clear impact of the type of precursor used and its chemical composition on the resulting mechanical parameters of the material. Composites containing GGBFS were characterised by their significantly higher strength. The basic product of the silica ash reaction in an alkaline environment is amorphous hydrated alkali-aluminosilicate (N-A-S$\mathrm{H})$ gel. An additive in the form of GGBFS introduces calcium into the structure of the material, which takes part in the creation of the products of geopolymerisation. In mixed systems, chemical interaction between the products of the alkaline activation of ash and GGBFS may result in the formation of complex structures, such as C-N-A-S-H gel [30]. Geopolymer binders with the addition of GGBFS are characterised by the fast increase and high values of their strength properties. In the case of a blended precursor, the highest strength values after 28 days of curing were observed for the material containing 50wt.\% SSA and 50wt.\% GGBFS in the binder. The average bending strength was approx. 5.0 MPa and the compressive strength was nearly 45.5 MPa. The results are around 30\% lower than those of the FA-GGBFS mixed binder [31]. Mixtures containing only SSA binders or SSA in combination with FA binders had a significantly lower strength. The chemical composition of the precursor is one of the main factors determining the properties of the geopolymer. $\mathrm{SiO}_{2}$ and $\mathrm{Al}_{2} \mathrm{O}_{3}$ oxides combined with alkaline metal cations are the basic building component of the geopolymer structure. The lower content of these oxides in SSA compared to FA was directly reflected in the strength of the material. The development of strength over time for the geopolymer with an SSA precursor was lower compared to FAbased mixtures. The difference after 28 days of curing was clearly noticeable. 


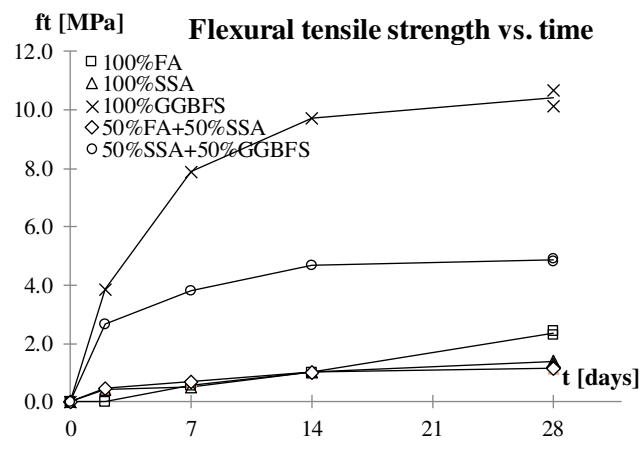

a)

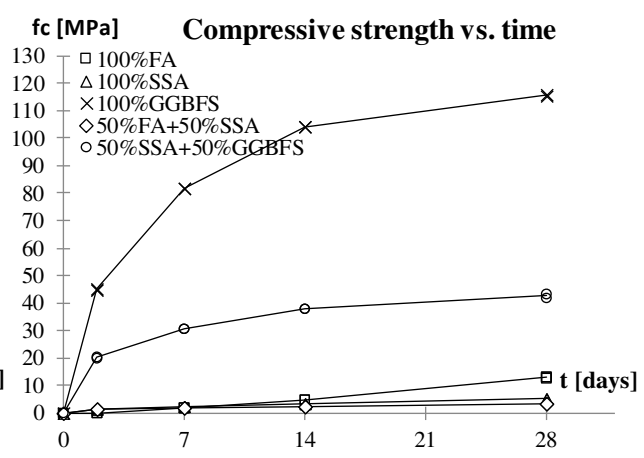

b)

Fig. 2. Changes of a) flexural and b) compressive strength as a function of curing time.

In addition to mechanical strength, the second analysed aspect was the possibility of the immobilisation of heavy metals from industrial waste materials in the geopolymer structure. For the precursors used in the form of SSA, FA and GGBFS, the total content of: $\mathrm{Sb}, \mathrm{As}$, $\mathrm{Cr}, \mathrm{Cd}, \mathrm{Cu}, \mathrm{Ni}, \mathrm{Pb}, \mathrm{Hg}$ and $\mathrm{Zn}$ was determined. The results are presented in Table 5. The properly prepared mortar samples were then subjected to leaching in order to determine the level of heavy metal binding in the geopolymer structure.

Table 5. Total heavy metal content in the waste raw materials.

\begin{tabular}{|l|c|c|c|c|c|c|c|c|c|}
\hline $\begin{array}{l}\text { Element } \\
\text { (mg/kg of dry mass) }\end{array}$ & $\mathbf{S b}$ & $\mathbf{A s}$ & $\mathbf{C r}$ & $\mathbf{Z n}$ & $\mathbf{C d}$ & $\mathbf{C u}$ & $\mathbf{N i}$ & $\mathbf{P b}$ & $\mathbf{H g}$ \\
\hline FA & 8.5 & 25 & 42 & 70 & $<8$ & 53 & 59 & 62 & 0.3 \\
\hline SSA & 14 & 9.3 & 466 & 3532 & $<8$ & 668 & 156 & 124 & 0.371 \\
\hline GGBFS & 6.2 & $<2$ & $<40$ & $<16$ & $<8$ & $<12$ & $<40$ & $<40$ & $<0.06$ \\
\hline
\end{tabular}

Of all the precursors used, SSA was characterised by the highest content of heavy metals. Particularly high values were determined for $\mathrm{Cr}, \mathrm{Cu}$, and $\mathrm{Zn}$. Compared to SSA, only fly ash showed higher As content, the content of other metals was much lower. GGBFS is the precursor least contaminated with heavy metals.

Table 6. Mass of heavy metal in water and the acceptable level of content for industrial waste.

\begin{tabular}{|c|c|c|c|c|c|c|c|c|c|}
\hline Mass [mg/l] & Sb & As & $\mathrm{Cr}$ & $\mathbf{Z n}$ & Cd & $\mathbf{C u}$ & $\mathbf{N i}$ & $\mathbf{P b}$ & $\mathbf{H g}$ \\
\hline $50 \% \mathrm{FA}+50 \% \mathrm{SSA}$ & 0.057 & 0.29 & $<0.2$ & $<0.08$ & $<0.04$ & $<0.06$ & $<0.2$ & $<0.2$ & $<0.0003$ \\
\hline $50 \% \mathrm{SSA}+50 \% \mathrm{GGBFS}$ & 0.038 & 0.058 & $<0.2$ & $<0.08$ & $<0.04$ & $<0.06$ & $<0.2$ & $<0.2$ & $<0.0003$ \\
\hline $100 \% \mathrm{FA}$ & 0.06 & 0.64 & $<0.2$ & $<0.08$ & $<0.04$ & $<0.06$ & $<0.2$ & $<0.2$ & $<0.0003$ \\
\hline $100 \%$ SSA & 0.058 & 0.12 & $<0.2$ & $<0.08$ & $<0.04$ & $<0.06$ & $<0.2$ & $<0.2$ & $<0.0003$ \\
\hline $100 \% \mathrm{GGBFS}$ & 0.043 & 0.029 & $<0.2$ & $<0.08$ & $<0.04$ & $<0.06$ & $<0.2$ & $<0.2$ & $<0.0003$ \\
\hline Inert wastes [32] & $<0.06$ & $<0.5$ & $<0.5$ & $<4$ & $<0.04$ & $<2$ & $<0.4$ & $<0.5$ & $<0.01$ \\
\hline $\begin{array}{l}\text { Non-hazardous wastes } \\
\text { [32] }\end{array}$ & $<0.7$ & $<2$ & $<10$ & $<50$ & $<1$ & $<50$ & $<10$ & $<10$ & $<0.2$ \\
\hline Hazardous wastes [32] & $<5$ & $<25$ & $<70$ & $<200$ & $<5$ & $<100$ & $<40$ & $<50$ & $<2$ \\
\hline $\begin{array}{l}\text { Sewage discharged into } \\
\text { water and soil [33] }\end{array}$ & $<0.3$ & $<0.1$ & $<0.5$ & $<2$ & $<0.2$ & $<0.5$ & $<0.5$ & $<0.5$ & $<0.03$ \\
\hline $\begin{array}{l}\text { Surface water intended } \\
\text { for the abstraction of } \\
\text { drinking water } \mathrm{A}_{3}[34]\end{array}$ & - & $<0.05$ & $<0.05$ & $<5$ & $\begin{array}{c}<0.00 \\
5\end{array}$ & $<0.5$ & $<0.2$ & $<0.05$ & $<0.001$ \\
\hline
\end{tabular}


The determined heavy metal content in water extract is presented in Table 6. Apart from antimony and arsenic, the content of all heavy metals was below the detection level. Since there are no legal acts regarding the leachability of heavy metals from geopolymer composites, the obtained leachability values were referred to the criteria of various categories of waste, i.e. inert, non-hazardous and hazardous. Regardless of the composition of geopolymer composites, the leachability of all heavy metals was below the limit, even for inert waste. Moreover, in all cases of the investigated geopolymers, the eluent composition meets the requirements for post-production wastewater. The exception are FAbased geopolymers, i.e 50\% FA+50\%SSA, and 100\%FA. It results from exceeding the allowed arsenic content, which has its source in the composition of fly ash. It is also worth noting that the eluent taken from the geopolymer composite made of GGBFS also meets the requirements for surface waters of $\mathrm{A}_{3}$ category.

\section{Conclusion}

This article has presented a preliminary analysis of the possibility of using SSA in geopolymer binder technology. Tests of the mechanical properties of geopolymer mortars containing SSA or mixtures of SSA with FA and SSA with GGBFS (1:1 ratios by weight) as precursors were carried out. The properties of the geopolymers depended mainly on the chemical composition of the precursor. The results of the conducted research indicate that the combination of SSA with GGBS is the most advantageous of all the tested solutions of SSA utilisation in geopolymer synthesis. The composite with this type of mixed precursor is characterised by a relatively fast increase and high values of strength properties. After only 2 days, the flexural strength was $2.7 \mathrm{MPa}$ and the compressive strength was $20 \mathrm{MPa}$. The values obtained after 28 were $5 \mathrm{MPa}$ and $45.5 \mathrm{MPa}$ for bending and compression strength, respectively.

The consistency loss and higher liquid demand of SSA in comparison to FA resulted in the need for using more alkaline solution. In further research, other possibilities to regulate the consistency of the mixture should be explored so as not to introduce excessive, unnecessary amounts of alkali that will not be built into the structure of the material. In addition, other proportions of mineral raw materials should also be considered in order to optimise the composition of the binder in terms of the selected properties.

The content of heavy metals ( $\mathrm{Sb}, \mathrm{As}, \mathrm{Cr}, \mathrm{Cd}, \mathrm{Cu}, \mathrm{Ni}, \mathrm{Pb}, \mathrm{Hg}, \mathrm{Zn}$ ) in industrial waste used was measured and the level of their leachability from the geopolymer structure was determined. In the vast majority of cases, the concentration level of heavy metals was below the limit of detection. The vast majority of the tested eluents taken from the prepared compositions of geopolymers meet the criteria for the leachability of heavy metals from waste materials, and in the case of the $100 \%$ GGBFS composite, it additionally meets the requirements for surface water.

This work has been financed by Polish National Agency for Academic Exchange under the International Academic Partnership Programme within the framework of the grant: E-mobility and sustainable materials and technologies EMMAT(PPI/APM/2018/1/00027).

\section{References}

1. B. Singh, G. Ishwarya, M. Gupta, S. K. Bhattacharyya, Constr. Build. Mater. 85, 78-90 (2015)

2. A. Koenig, A. Herrmann, S. Overmann, F. Dehn, Constr. Build. Mater. 151, 405-413 (2017) 
3. D. L. Y. Kong, J.G Sanjayan, Cem. Concr. Compos. 30, 986-991 (2008)

4. Z. Ji, Y. Pei, J. Environ. Manage. 231, 256-267 (2019)

5. J. Małolepszy, Zesz. Nauk. AGH. Ceram. 56, (1989)

6. A. Koleżyński, M. Król, M. Żychowicz, J. Mol. Struct. 1163, 465-471 (2018)

7. J. Payá, J. Monzó, M. V. Borrachero, M. M Tashima, Handbook of Alkali-Activated Cements, Mortars and Concretes (2015)

8. E. Nimwinya, W. Arjharn, S. Horpibulsuk, T. Phoo-Ngernkham, A. Poowancum, J. Clean. Prod. 119, 128-134 (2016)

9. P. Drechsel, M. Qadir, D. Wichelns, Economic asset in an urbanizing world (2015)

10. A. Kelessidis, A.S. Stasinakis, Waste Manag. 32, 1186-1195 (2012)

11. D. F. Lin, C. H. Weng, J. Environ. Eng. 127, 10 (2001)

12. L. Chen, D. F. Lin, Constr. Build. Mater. 23, 3312-3320 (2009)

13. I. J. Chiou, K. S. Wang, C. H. Chen, Y. T. Lin,. Waste Manag. 26, 1453-1461 (2006)

14. M. Cyr, M. Coutand, P. Clastres, Cem. Concr. Res. 37, 1278-1289 (2007)

15. C. J. Lynn, R. K. Dhir, G. S. Ghataora, R. P. West, Constr. Build. Mater. 98, 767-779 (2015)

16. Z. Chen, C. S. Poon, Constr. Build. Mater. 154, 791-803 (2017)

17. M. M. Tashima, L. Reig, M. A. Santini, J. C. Moraes, J. L. Akasaki, J. Payá, M. V. Borrachero, L. Soriano, Waste Biomass Valori. 8, 1441-1451 (2017)

18. S. Chakraborty, B. W. Jo, J. H. Jo, Z. Baloch, J. Clean. Prod. 153, 253-263 (2017)

19. N. Yamaguchi, K. Ikeda, J. Ceram. Soc. Japan. 118, 107 (2010)

20. R. C. M. Paulnath, A. M. M. Aski, F. Hamsath, S. Jasekan, C. Pathirana, The 4th International Symposium on Advances in Civil and Environmental Engineering Practices for Sustainable Development (Sri Lanka, 2019)

21. M. Wang, T. Zhu, L. Cheng, B. Andserson, X. Zhao, D. Wang, A. Ding, J. Environ. Sci. 63, 156-173 (2018)

22. V. Nikolić, M. Komljenović, N. Marjanović, Z. Baščarević, R. Petrović, Ceram. Int. 40, 8479-8488 (2014)

23. Q. Y.Chen, M. Tyrer, C. D. Hills, X. M. Yang, P. Carey, Waste Manag. 29, 390-403 (2009)

24. D. Dermatas, X. Meng, Eng. Geol. 70, 377-394 (2003)

25. Y. Hu, P. Zhang, J. Li, D. Chen, J. Hazard. Mater. 299, 149-157 (2015)

26. W. Nocuń-Wczelik, Cement Lime Concrete 5, 188-191 (1997)

27. J. Deja, Cem. Concr. Res. 32, 1971-1979 (2002)

28. R. A. A. Boca Santa, C. Soares, H. G. Riella,. J. Hazard. Mater. 318, 145-153 (2016)

29. Y. Yakubu, J. Zhou, D. Ping, Z. Shu, J. Environ. Manage. 207, 243-248 (2018)

30. I. Ismail, S. A. Bernal, J. L. Provis, R. San Nicolas, S. Hamdan, J. S. J. van Deventer, Cem. Concr. Compos. 45, 125-135 (2014)

31. M. Sitarz, I. Hager, M. Choińska, Energies, 13, 1135-1147 (2020)

32. Dz.U. RP Poz. 1277/1.09.2015 - Polish regulation

33. Dz.U. RP Poz. 984 Nr. 137/2006 - Polish regulation

34. Dz.U. RP Poz. 2268/29.08.2019 - Polish regulation 